\title{
The insufficiency of a finite state model for verbal reconstructive memory
}

\author{
Martin D. S. Braine \\ WALTER REED ARMY INSTITUTE OF RESEARCH
}

\begin{abstract}
Abstraet
A variant of conventional memory techniques (Verbal Reconstructive Memory) is outlined which appears especially suitable for the laboratory study of grammar acquisition. The method is illustrated by means of an experiment in which "what is learned" cannot be represented by finite state rules.
\end{abstract}

\section{Introduetion}

This paper illustrates and somewhat extends an experimental method for the laboratory study of grammar acquisition used by Smith (1963). Ss are exposed to a set of strings ("sentences"), which are characterized by some regularities of construction. The regularities derive from the fact that the strings are a subset of the possible strings generated by a grammar. The strings are sufficiently numerous that only a small proportion can be learned "by rote." After exposure, the Ss are tested to discover what regularities they have learned. Various tests are possible; below, a recognition test, a recall test, and a sentence-completion ('frame") test are used. The essence of the method is that recognition involves detection of regularities of structure (i.e., is equivalent to a judgment of grammaticality), and that other tests investigate what regularities $\mathrm{S}$ has learned by testing his ability to reconstruct the presented strings. Smith (1963) found that unpresented strings, presumably reconstructed by Ss, appeared frequently in their free recall.

The method appears particularly suitable for investigating the kinds of grammatical regularities Ss areable to learn. There are a number of models in the literature which can be construed as theories of the kinds of regularities that are learnable, e.g., (1) phrasestructure systems (Chomsky, 1963), notably the contextsensitive and context-free subclasses, (2) the writer's position-learning proposals (Braine, 1963a, 1963b), (3) finite state systems. The method described would permit the sufficiency of such theories to be investigated, for a class of materials (e.g., semantically empty strings) and situations (serial exposure to strings). In the experiment reported, the regularities learned are not describable by a finite state grammar.

\section{Procedure}

The strings presented may be schematized as follows: $a x_{1} b, a x_{2} b, a x_{3} b, a x_{4} b, a x_{5} b, a x_{6} b ; a x_{7} b, a x_{8} b, a x_{9} b, a x_{10} b, a x_{11} b$, $\mathrm{ax}_{12} \mathrm{~b} ; \mathrm{px}_{1} \mathrm{q}, \mathrm{px}_{2} \mathrm{q}, \mathrm{px}_{3} \mathrm{q}, \mathrm{px}_{4} \mathrm{q}, \mathrm{px}_{5} \mathrm{q}, \mathrm{px}_{6} \mathrm{q} ; \mathrm{px}_{13} \mathrm{q}, \mathrm{px}_{14} \mathrm{q}, \mathrm{px}_{15} \mathrm{q}$, $\mathrm{px}_{16} \mathrm{q}, \mathrm{px}_{17} \mathrm{q}, \mathrm{px}_{18} \mathrm{q}$. ( $\mathrm{a}=$ ane; $\mathrm{b}=$ kivil; $\mathrm{p}=$ foo; $\mathrm{q}=$ slet; $\mathrm{x}_{1-18}=$ eft, henuf, loce, porge, shang, uckle, blonce, cheg, darth, eena, sorum, trool, ath, cordwee, hile, mairn, niss, yirt.) These 24 strings were expanded to 36 by presenting 12 of the strings ( 3 in each group of 6 ) twice over. The 36 strings were arranged in four different orders, and the four sets (144 strings) were read on to tape with about 2 sec. pausè between each string.
The Ss were run in groups of two to four. To familiarize them with the words they first listened to two readings of the vocabulary in alphabetical order, and compared the tape recorded words with the spellings shown on a typewritten list. Then Ss listened to 72 tape recorded strings (two sets of 36), without access to any written material, and with the instruction to say each string to themselves during the pause following it. There followed a free recall test and a recognition test (Test I). Then Ss listened to the remaining 72 tape recorded strings under the same conditions as before. There followed another free recall test, another recognition test (Test II), and, terminally, the "frame" test.

In the free recall tests Ss were instructed to write down 10 strings that they remembered; they were told they could "guess," but not to write down any strings they were sure they had not heard. The alphabetically-ordered vocabulary list was available as a memory aid.

Each recognition test consisted of 20 randomly ordered strings, with different strings used in each test. On hearing each string Ss wrote "Yes" if they thought they had heard the string before, and "No" if not. The written vocabulary list was not available. Each test comprised: (a) four strings, two aXb and two $\mathrm{pXq}$, using X-words that had previously been exposed in both the a...b and p...q frames ("BOTH" in Fig. 1); (b) four strings, two aXb and two pXq, using $\mathrm{X}$-words that had previously been exposed only in the frame in which they appeared in the test, e.g., $\mathrm{ax}_{7} \mathrm{~b}, \mathrm{px}_{13} \mathrm{q}$ ("ONE" in Fig. 1); (c) four strings, two $\mathrm{aXb}$ and two $\mathrm{pXq}$, using $\mathrm{X}$-words that had not previously been exposed in the frame in which they appeared in the test, e.g., $\mathrm{ax}_{13} \mathrm{~b}, \mathrm{px}_{7} \mathrm{q}$ ("IMPORT" in Fig. 1); (d) four strings, two aXq and two $\mathrm{pXb}$, using any $\mathrm{X}$-words; (e) four strings, $\mathrm{aXX}, \mathrm{XXb}$, pXX, XXq, using any X-words. Only (a) and (b) had actually been exposed. Ss who learn the $a--b$ and $p--q$ concords, but learn of the $\mathrm{X}$-words only that they occur second, should answer "Yes" to (a), (b) and (c), and "No" to (d) and (e). Ss who learn the ordinal position of the words but fail to learn the concord should answer "Yes" to (a) - (d) and "No" to (e).

The "frame" test was introduced with "You may have noticed that some of the sentences began with (a) and ended with (b), and that others began with $(p)$ and ended with $(q)$." Ss were given the vocabulary list and asked to list the words that they remembered hearing in the context $a . . . b$, and then to list the words they remembered in p...q.

Ss were six high school students, aged 15-16, and six nonprofessional staff.

\section{Results}

The recognition tests (Fig. 1) show clearly that Ss tended to accept all strings of the form a...b and p...q with an $\mathrm{X}$-word in between, regardless of whether or not they had actually heard the string before. The difference between the number of "imports" and the number of strings aXq and $\mathrm{pXb}$ accepted was significant ( $p<.01$, and .001, for Tests I and II, respectively). There were no significant differences among the categories "both," "one," and "import."

The data from the first recall test will be ignored, since six Ss made errors of concord, or worse. On the second recall test, 10 Ss wrote only strings of the form $\mathrm{aXb}$ and $\mathrm{pXq}$, using both frames about equally. These Ss had presumably learned the concord. As might be expected, the free recall test elicited apparently "rote" 


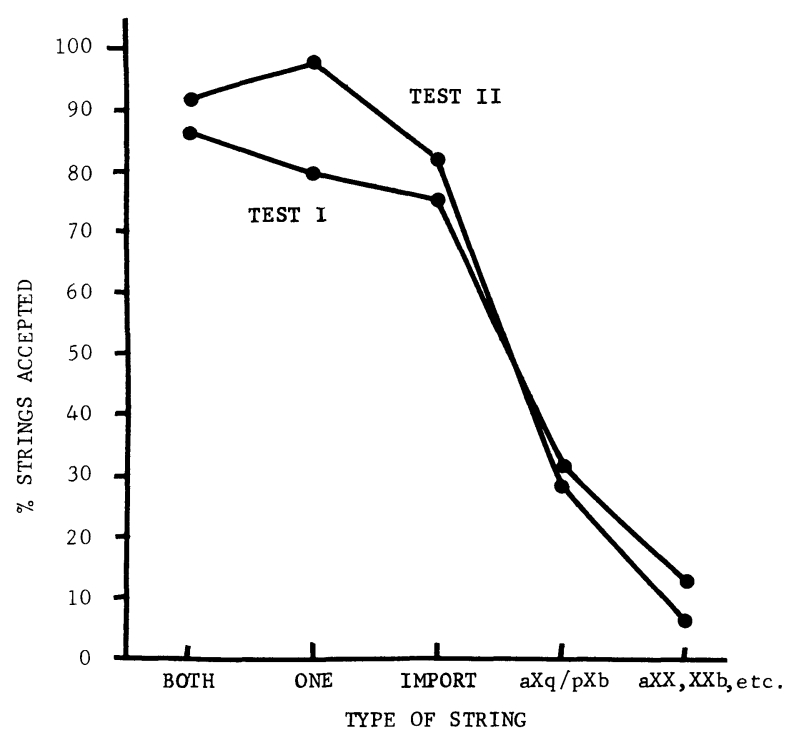

Fig. 1. Percentages of strings of each type "recognized" in the recognition tests.

learned strings preferentially; nevertheless, these 10 Ss wrote an average of 1.1 strings that had not been exposed.

The "frame" test results are relevant only for the 10 Ss who had learned the concord. In the a...b frame, they listed an average of 4.8 of the six words exposed in both frames, 4.5 of the six words exposed only in this frame, and 3.5 of the six words exposed only in the other frame. In the p...q frame, the corresponding figures were $4.9,5.0$, and 3.6. Thus, Ss listed many words they had not heard in a given context, though somewhat less frequently $(p<.05)$ than words they had heard.

\section{Discussion}

The evidence indicates that what is learned is approximately the following: that $a$ and $p$ go first, that $b$ and $q$ go last, that $b$ is contingent on a and $q$ on $p$, and that the remaining words go second (or, in the middle). This description uses the terminology of the writer's position-learning theory. A possible translation into the formal notation of a phrase-structure grammar might be: $\mathrm{S} \longrightarrow \mathrm{aXb}, \mathrm{pXq} ; \mathrm{X} \longrightarrow \mathrm{x}_{1}, \mathrm{x}_{2}, \ldots \mathrm{x}_{18}$. (" $\mathrm{S}$ "' = "sentence," "->" = "may be rewritten as"; capital letters designate classes, and lower-case letters words.) ${ }^{1} \mathrm{~A}$ finite state grammar is confined to rules of the form
$\mathrm{A} \longrightarrow \mathrm{bC}$ and $\mathrm{A} \longrightarrow \mathrm{b}$ (Chomsky, 1963). Using such rules, the 24 presented strings are exactly described as follows $\mathrm{S} \longrightarrow \mathrm{aY} ; \mathrm{Y} \longrightarrow \mathrm{x}_{1} \mathrm{~B}, \mathrm{x}_{2} \mathrm{~B}, \ldots \mathrm{x}_{12} \mathrm{~B}$; $\mathrm{B} \longrightarrow \mathrm{b} ; \mathrm{S} \longrightarrow \mathrm{pZ} ; \mathrm{Z} \longrightarrow \mathrm{x}_{1} \mathrm{Q}, \ldots \mathrm{x}_{6} \mathrm{Q}, \mathrm{x}_{13} \mathrm{Q}, \ldots$ $\mathrm{x}_{18} \mathrm{Q} ; \mathrm{Q} \rightarrow \mathrm{q}$. Since Ss tended to think they heard $\mathrm{x}_{13-18}$ in a...b and $\mathrm{x}_{7-12}$ in $\mathrm{p} . . \mathrm{q}$, a finite state description of what is learned would require the assumption that Ss invented the additional rules $\mathrm{Y} \longrightarrow \mathrm{x}_{13} \mathrm{~B}$, $\ldots \mathrm{x}_{18} \mathrm{~B}$ and $\mathrm{Z} \rightarrow \mathrm{x}_{7} \mathrm{Q}, \ldots \mathrm{x}_{12} \mathrm{Q}$, which have no exemplars in the exposed strings.

It is likely that if the Ss were given enough exposure to the 24 presented strings they would eventually learn them; some specific learning is already apparent in the recall and frame tests. In the position-learning terminology, Ss would learn which X-words went between a and $b$, and which between $p$ and $q$. A description in terms of a finite state grammar would have to represent the Ss as unlearning the rules they had previously invented.

Finite state rules are clearly not what is learned in this experiment. It follows that Ss can learn grammatical regularities describable by more powerful rules than the two forms $\mathrm{A} \longrightarrow \mathrm{bC}$ and $\mathrm{A} \longrightarrow \mathrm{b}$, e.g., $\mathrm{A} \longrightarrow \mathrm{bCd}$ in this experiment. Given the known insufficiency of the finite state model for natural languages (Chomsky, 1957), its insufficiency in a laboratory grammar acquisition task is not surprising.

The reconstructive memory method illustrated appears to be a very exploitable technique for studying grammar acquisition. Generalizing from laboratory results to natural language acquisition will of course be difficult. However, it seems not unreasonable to suggest that, in respect to grammar acquisition, first language learning is essentially a massive reconstructive memory experiment conducted by nature with the young of the human species.

\section{Referenees}

BRAINE, M. D. S. On learning the grammatical order of words. Psychol. Rev., 1963a, 70, 323-348.

BRAINE, M. D. S. Learning language structures. American Psychological Association meetings, 1963b. (Mimeographed)

CHOMSKY, N. Syntactic structures. The Hague: Mouton, 1957. CHOMSKY, N. Formal properties of grammars. In R. D. Luce, R. R. Bush, \& E. Galanter (Eds.), Handbook of mathematical psychology. Vol. II. New York: Wiley, 1963.

SMITH, KIRK S. Recall of paired verbal units under various conditions of organization. Ph.D. dissertation, University of Minnesota, 1963.

\section{Note}

1. The $\mathrm{a}-\mathrm{-b}$ and $\mathrm{p}--\mathrm{q}$ contingencies could be represented by contextsensitive rather than linear rules, thus: $S \longrightarrow$ FXG; $F \longrightarrow a, p$; $\mathrm{G} \longrightarrow \mathrm{b}$ in context $\mathrm{aX} \ldots, \mathrm{G} \longrightarrow \mathrm{q}$ in context $\mathrm{pX} \_; \mathrm{X} \longrightarrow \mathrm{x}_{1}, \ldots$ $\mathrm{x}_{18}$. However, the linear grammar appears simpler. 